\title{
Em perigo/perigoso: racismo esquemático e paranoia branca ${ }^{1}$
}

\author{
Judith Butler \\ Tradução: Fabiana A. A. Jardim² \\ ORCID: 0000-0001-8694-0578 \\ Revisão técnica: Jacqueline Moraes Teixeira² \\ ORCID: 0000-0001-9884-353X \\ Revisão técnica: Sebastião Rinaldi ${ }^{3}$ \\ ORCID: 0000-0001-6272-263X
}

\section{Resumo}

Originalmente, o texto foi publicado em 1993, como capítulo do livro editado por Robert Gooding-Williams, dedicado à análise dos acontecimentos desdobrados a partir do espancamento de Rodney King, um homem negro de 27 anos, por policiais brancos, em março de 1991, na cidade de Los Angeles. A violência foi registrada em vídeo e gerou indignação pública, tornando possível que quatro policiais fossem indiciados criminalmente. Levados a júri, todos foram absolvidos, o que desencadeou um ciclo de protestos ao longo de quase uma semana; duramente reprimidos pela mesma força policial que se lançou sobre Rodney King, deixaram mais de sessenta mortos e mais de dois mil feridos. A contribuição de Judith Butler se dedica a compreender como foi possível que acusação e defesa tenham, ambas, recorrido à gravação. Como um mesmo conjunto de imagens pôde ter sido "visto" como demonstração da violência policial e como sua justificativa? A autora identifica a existência de um campo de visibilidade racialmente saturado, que circunscreve a percepção de pessoas que se compreendem enquanto brancas, cuja identidade se sustenta na projeção da violência sobre o outro racializado enquanto negro. Nesse sentido, a absolvição se torna compreensivel como efeito de uma episteme racista, que toma o corpo masculino negro de Rodney King como origem e razão da violência que lhe foi impingida, isentando os policiais de responsabilidade. Daí a importância estratégica do ato público de ler e reler tais imagens, postas a funcionar num enquadramento que se sustenta num regime racista de produção e distribuição das imagens, que frequentemente concentra as possibilidades de torná-las legíveis.

\section{Palavras-chave}

Racismo - Violência policial - Levantes urbanos - Imagem - Branquitude.

1- Original: Endangered/Endangering: Schematic Racism and White Paranoia. In: Gooding-Williams, Robert (ed.) Reading Rodney King/Reading Urban Uprising. London/New York: Routledge, 1993, pp.15-22. Publicado com autorização da autora, a quem muito agradecemos.

2- Universidade de São Paulo, São Paulo, Brasil. Contatos: fajardim@usp.br; jamoteka@gmail.com; sebastiaorinaldi@gmail.com. 


\section{Endangered/endangering: schematic racism and white paranoia}

\section{Abstract}

The text was originally published in 1993 as a chapter in the book Reading Rodney King, Reading Urban Uprising, edited by Robert Gooding-Williams. It is dedicated to the analysis of the series of events triggered from the beating of Rodney King, a 27-year-old black man, by white policemen in March 1991 in the city of Los Angeles. The violence was recorded on video and generated public outrage, making it possible for four police officers to be criminally indicted. Taken to the jury, they were all acquitted, which sparked a cycle of protests over a week; the protests were harshly repressed by the same police force that threw itself at Rodney King and left more than sixty dead and more than two thousand wounded. Judith Butler's contribution is dedicated to understanding how it was possible that prosecution and defense both resorted to the recording. How could the same set of images have been "seen" as a demonstration of police violence and as its justification? The author identifies the existence of a racially saturated field of visibility that circumscribes the perception of people who understand themselves as white, whose identity is sustained by the projection of violence on the other racialized as black. In this sense, absolution becomes understandable as the effect of a racist episteme, which takes Rodney King's black male body as the origin and reason for the violence imposed on him, exempting the police from responsibility. Hence the strategic importance of the public act of reading and rereading the images, which are put into operation within a framework sustained by a racist regime of production and distribution of images that also, very often, retains the possibility of making them readable.

\section{Keywords}

Racism - Police violence - Urban uprising - Images - Whiteness.

Os advogados de defesa da polícia no caso de Rodney King argumentaram que os policiais estavam em perigo e que Rodney King era a fonte de tal perigo. A argumentação se fez a partir de várias fontes: comentários que ele fez, atos que se recusou a realizar quando mandado, e o vídeo altamente publicizado, gravado no local e televisionado amplamente, antes e durante o julgamento. Durante o julgamento, o vídeo foi exibido ao mesmo tempo em que a defesa o comentava, e assim podemos presumir que alguma convergência entre palavra e imagem produzia a "evidência" para os jurados do caso. 0 vídeo mostra um homem sendo brutalmente espancado, repetidamente, e sem resistência visível; então, a questão é: como pôde este vídeo ser usado como evidência de que o corpo sendo agredido era ele mesmo a fonte do perigo, a ameaça de violência, e, além disso, que o corpo espancado de Rodney King carregava uma intenção de ferir, e ferir precisamente aqueles policiais que ou empunhavam os cassetetes contra ele ou permaneciam em volta 
dele? No tribunal de Simi Valley, o que muitos tomaram como evidência inquestionável contra a polícia foi, ao invés disso, apresentada para estabelecer a vulnerabilidade policial, ou seja, para apoiar a alegação de que Rodney King ameaçava a polícia. Mais tarde, uma jurada relatou que acreditava que Rodney King tinha "controle total" da situação. Como essa proeza de interpretação foi alcançada?

Que ela tenha sido alcançada não é consequência de ignorar o vídeo, mas, ao contrário, de reproduzir o vídeo no interior de um campo de visibilidade racialmente saturado. Se o racismo impregna as percepções brancas, estruturando o que pode ou não aparecer no interior do horizonte da percepção branca, então, em que medida ele interpreta a priori a "evidência visual"? E como, então, tal "evidência" deve ser lida, e publicamente lida, contra a disposição racista do visível, que preparará e chegará às suas próprias percepções invertidas sob a rubrica do "que é visto"?

Acima, escrevi sem hesitação que "o vídeo mostra um homem sendo brutalmente espancado". No entanto, parece que o júri no Simi Valley sustentou que eles "viram” um corpo ameaçando a polícia, e enxergaram nos golpes ações razoáveis de policiais em autodefesa. A partir dessas duas interpretações emerge, portanto, uma disputa no interior do campo visual, uma crise na certeza do que é visivel, produzida por meio da saturação e esquematização deste campo com as projeções invertidas da paranoia branca. A representação visual do corpo masculino negro espancado na rua por policiais e seus cassetetes foi tomada por aquele quadro de interpretação racista para construir King como agente da violência, cuja agência está implícita de modo fantasmático na narrativa precedente e antecedente aos fotogramas mostrados. Observando King, a paranoia branca forma uma sequência de inteligibilidade narrativa que consolida a figura racista do homem negro: "Ele tinha lhes ameaçado e agora está sendo contido de uma maneira justificada". "Se pararem de bater nele, ele irá liberar sua violência, e agora está sendo contido a partir de uma justificativa”. A mão de King afastada de seu corpo e a palma sustentada acima de sua cabeça são lidas não como autoproteção, mas como momentos incipientes de ameaça física.

Como levamos em conta essa reversão de gesto e intenção em termos de uma esquematização racial do campo do visível? Essa é uma transvaloração específica da agência própria a uma episteme racializada? E a possibilidade de tal reversão coloca em questão se o que é "visto" não é, em parte, sempre de partida uma questão do que certa episteme racista produz como visível? Pois se os jurados chegaram a ver no corpo de Rodney King um perigo à lei, então essa "visão" requer ser lida como aquilo que foi selecionado, cultivado, regulado - de fato, policiado - no curso do julgamento. Isso não é simplesmente ver, um ato de percepção direta, mas de produção racial do visível, o processo das restrições raciais sobre o que significa "ver". Na verdade, o julgamento conclama ser lido não somente enquanto lição dos modos racistas de ver, mas enquanto uma produção repetida e ritualística da negritude (uma instância a mais do que Ruth Gilmore, descrevendo a cena do vídeo, nomeou como um ato de "construção nacional"). Trata-se de um ver que é um ler, isto é, uma construção contestável, mas que ainda assim se passa por "ver", uma leitura que se tornou, para aquela comunidade branca, e para muitos outros, o mesmo que ver. 
Se o que se oferece aqui sobre e contra o que o júri viu é um ver diferente, um ordenamento diferente do visível, trata-se de algo igualmente contestável - como vimos no temporário triunfo interpretativo da construção, pelo advogado de defesa, de King como perigoso. Afırmar que a vitimização de King é manifestamente verdadeira é o mesmo que pressupor que alguém apresenta o caso a um conjunto de sujeitos que sabem como ver; imaginar que o vídeo "fala por si mesmo" é, claro, para muitos de nós, obviamente verdadeiro. Mas se o campo do visível é um terreno racialmente contestado, então será politicamente imperativo ler tais vídeos agressivamente, repetir e tornar públicas tais leituras, mesmo que apenas para fazer avançar uma hegemonia antirracista sobre o campo visual. Poderia parecer, num primeiro momento, que sobre e contra esse fracasso hediondo em enxergar a brutalidade policial, é necessário restaurar o visível como evidência. Mas o que o julgamento e suas conclusões terriveis nos ensinam é que não há simples recurso ao visível, à evidência visual, que [esta] ainda e sempre convoca a ser lida, que é desde sempre uma leitura, e que para estabelecer [que houve] o dano sobre as bases de evidências visuais, uma leitura agressiva da evidência é necessária.

Não é uma questão, portanto, de negociar entre o que é “visto", de um lado, e uma "leitura" que é imposta sobre a evidência visual, de outro. Em certo sentido, o problema é ainda pior: na medida em que há uma organização e disposição racista do visível, ela funcionará para circunscrever o que se qualifica como evidência visual, de tal modo que, em alguns casos, é impossível estabelecer a "verdade" da brutalidade racista por meio do recurso à evidência visual. Quando o visual está completamente esquematizado pelo racismo, a "evidência visual" à qual nos referimos irá sempre e somente refutar as conclusões nela baseadas; é possível, no interior dessa episteme racista, que nenhuma pessoa negra possa recorrer ao visível enquanto terreno seguro de evidência. Considere que fosse possivel traçar uma linha de inferência a partir de um corpo negro masculino sem movimentos e espancado na rua e a conclusão de que esse mesmo corpo estava com "controle total", pleno de "intenções perigosas". 0 campo visual não é neutro à questão da raça; é ele mesmo uma formação racial, uma episteme hegemônica e persuasiva.

\footnotetext{
***

No mundo branco, o homem de cor encontra dificuldades na elaboração de seu esquema corporal. 0 conhecimento do corpo é unicamente uma atividade de negação. É um conhecimento em terceira pessoa. Em torno do corpo reina uma atmosfera densa de incertezas. Sei que, se quiser fumar, terei de estender o braço direito e pegar o pacote de cigarros que se encontra na outra extremidade da mesa. Os fósforos estão na gaveta da esquerda, é preciso recuar um pouco. Faço todos esses gestos não por hábito, mas por um conhecimento implícito. Lenta construção de meu eu enquanto corpo, no seio de um mundo espacial e temporal, tal parece ser o esquema.

[...] Elaborei, abaixo do esquema corporal, um esquema histórico-racial. Os elementos que utilizei [me foram fornecidos] pelo outro, o branco, que os teceu para mim através de mil detalhes, anedotas, relatos. Eu acreditava estar construindo um eu fisiológico, equilibrando o espaço, localizando as sensações, e eis que exigiam de mim um suplemento.
} 
“Olhe, um preto!” Era um stimulus externo, me futucando quando eu passava. Eu esboçava um sorriso.

“Olhe, um preto!” É verdade, eu me divertia.

"Olhe, um preto!" 0 círculo fechava-se pouco a pouco. Eu me divertia abertamente.

“Mamãe, olhe o preto, estou com medo!” Medo! Medo! E começavam a me temer. Quis gargalhar até sufocar, mas isso tornou-se impossivel." (FANON, 2008, p. 104-105).

Frantz Fanon oferece aqui uma descrição de como o corpo negro masculino é constituído por meio do medo e de um nomear e ver: "Olhe, um preto!", em que o "olhe" é tanto um apontar como um ver, um apontar do que há para ser visto, um apontar que circunscreve um corpo perigoso, um indicativo racista que transmite seu próprio perigo ao corpo para que aponta. Aqui, o "apontar" não é apenas um indicativo, mas um prenúncio esquemático de uma acusação - acusação que carrega a força performativa de constituir aquele perigo que teme e do qual se defende. Em sua teoria claramente masculinista, Fanon demarca o sujeito como homem negro e o Outro como homem branco. Talvez devêssemos, no momento, deixar o masculinismo da cena em seu lugar; pois há, no interior do medo racista do homem branco em relação ao corpo negro masculino uma clara ansiedade sobre a possibilidade de troca sexual. Portanto, há referências repetidas ao "rabo" de Rodney King pelos policiais em seu entorno e a circunscrição homofóbica de tal lócus de sodomia como espécie de ameaça.

$\mathrm{Na}$ narração de Fanon sobre a interpelação racista, o corpo negro é circunscrito como perigoso, antes de qualquer gesto, de qualquer erguer de mão, e o leitor branco infantilizado é posicionado na cena como alguém indefeso em relação ao corpo negro, alguém que por definição precisa da proteção de sua mãe ou, talvez, da polícia. 0 medo é que certa distância física será ultrapassada e que a santidade virginal da branquitude estará ameaçada por tal proximidade. A polícia, portanto, está estruturalmente posicionada para proteger a branquitude contra a violência. A violência é a ação iminente daquele corpo negro masculino. E, porque no interior desse esquema imaginário a polícia protege a branquitude, sua própria violência não pode ser lida enquanto tal; porque o corpo negro masculino, antes de qualquer vídeo, é o lugar e fonte de perigo, uma ameaça; o esforço policial para subjugar este corpo, mesmo que por antecipação, está justificado a despeito das circunstâncias. Ou melhor, a convicção dessa justificação reorganiza e ordena as circunstâncias para se adequar a essa conclusão.

0 que me assombrou na manhã após a proclamação do veredito foram os relatos que reiteravam a produção fantasmática da "intenção", que era inscrita e lida a partir do corpo paralisado de Rodney King na rua, sua intenção de ferir, de colocar em perigo. 0 vídeo foi utilizado como 'evidência' para apoiar a reivindicação de que o corpo negro masculino - paralisado no chão, recebendo golpes - estava ele mesmo produzindo tais golpes, em vias de produzi-los. Ele era a ameaça iminente de um golpe e, assim, era ele próprio responsável pelos golpes recebidos. Aquele corpo recebeu, portanto, tais ataques em troca daqueles que estava prestes a desferir, golpes que estavam naquele corpo em seus gestos essenciais, mesmo que o único gesto que pode ser visto realizando é erguer suas mãos para afastar os golpes contra si. De acordo com esta episteme racista, ele é 
espancado em troca dos golpes que nunca desferiu. No entanto, ele, em virtude de sua negritude, está sempre prestes a desferir.

Aqui podemos ver a dissociação da intencionalidade violenta das ações policiais e o investimento dessas mesmas intenções sobre aquele que recebe os golpes. Como essa dissociação e atribuição de intencionalidade violenta é possível? E como foi reproduzida na pedagogia racista dos advogados de defesa, implicando, desse modo, os advogados de defesa em uma afiliação racista simpática à polícia, convidando os jurados a aderir a essa comunidade de vitimadores vitimizados? Os advogados procederam cultivando a identificação com a paranoia branca na qual uma comunidade branca está sempre e somente protegida pela polícia, contra a ameaça da qual o corpo de Rodney King é emblemático, bastante longe de qualquer ação que possa se dizer que performou ou que parece pronto a performar. Esta é uma ação que o corpo negro masculino está sempre performando no imaginário racista - e sempre o fez antes de qualquer vídeo. A identificação com a paranoia policial selecionou, produziu e consolidou naquele júri um modo de reconstituir um imaginário racista branco que se posiciona como se fosse um enquadramento não marcado do campo do visível, reivindicando a autoridade da "percepção direta".

A interpretação do vídeo no julgamento precisou trabalhar com possíveis lugares de identificação oferecidos: Rodney King, os policiais que o cercavam, aqueles que ativamente o espancavam, aqueles que testemunhavam, o olhar do câmera e, por implicação, do espectador branco que talvez sinta ultraje moral, mas que também assiste à distância, de repente instalado na cena como jornalista encoberto. De algum modo, o júri pôde ser convencido da inocência policial por meio de uma orquestração tática de tais identificações, pois, em certo sentido, todos são a testemunha branca, separada do local ostensivo de perigo negro por um círculo policial; eles são a polícia, executores da lei, circundando aquele corpo, batendo nele, novamente. Eles são, talvez, também King, mas "lavados de branco" /whitewashed/: os golpes que ele sofre são tomados como os golpes que eles poderiam sofrer se a polícia não os estivesse protegendo dele. Portanto, o perigo físico no qual King foi gravado é transferido a eles; eles se identificam com essa vulnerabilidade, mas a constroem como sua, a vulnerabilidade da branquitude, refigurando King como a ameaça. 0 perigo que acreditam sempre correr, em virtude de sua branquitude (branquitude como episteme que opera a despeito da existência de jurados não brancos). Isso completa o circuito da paranoia: as projeções de sua própria agressão, e a subsequente visada dessa projeção como ameaça externa.

0 tipo de "ver" que a polícia encenou e o tipo de "ver" que o júri reencenou constituem uma violência adicional, performada por meio do descrédito e projeção do espancamento violento. Os golpes contra Rodney King são entendidos como retribuição justa, de fato, defesas contra os perigos que são "vistos" emanando de seu corpo. Aqui, "ver" e atribuir são indissolúveis. Atribuir violência ao objeto de violência é parte do mecanismo mesmo que recapitula a violência, e faz da "visão" do júri cúmplice com a violência policial.

Os advogados de defesa dividiram o vídeo em frames, congelando a cena, de maneira que o gesto, a mão levantada, fosse destacada de seu lugar temporal na narrativa visual. 0 vídeo não é apenas violentamente descontextualizado, mas violentamente recontextualizado; é exibido sem trilha sonora simultânea que, caso existisse, estaria 
abarrotada de insultos raciais e sexuais contra Rodney King. No lugar de ler este testemunho junto com o vídeo, os advogados de defesa ofereceram a imagem congelada, a magnificação da mão levantada como figura hiperbólica da ameaça racial, interpretada e reinterpretada como gesto de violência pressagiada, um gesto em vias de sê-lo, o primeiro sinal de tal, violento em si mesmo. Aqui, o "ver" antecipatório é claramente um "ler", um ler que reencena a negação e a paranoia que permitem e defendem a brutalidade.

Contra e sobre essa leitura é exigida uma contraleitura agressiva - uma leitura que os promotores falharam em performar, que poderia ter exposto, por meio de um tipo distinto de reiteração, o que Fanon nomeou como "esquema histórico-racial" pelo qual a "visão" da negritude toma lugar ${ }^{3}$. Em outras palavras, é necessário ler não somente o "evento" da violência, mas o esquema racista que lhe orquestra e traz interpretação, que fragmenta a intenção violenta do corpo que a exerce e a atribui àquele que a recebe.

Se o gesto ampliado pode ser lido como evidência que apoia a teoria de que Rodney King está "no controle", "totalmente", do cenário em sua íntegra; [se pode ser lido] como evidência de suas próprias intenções ameaçadoras, logo, um circuito é produzido de maneira fantasmática em que King é a origem, a intenção e o objeto de idêntica brutalidade. Em outras palavras, se é sua violência que impele a sequência causal e se seu corpo recebe os golpes, então, de fato, ele espanca a si mesmo: ele é a origem e o fim da violência, ele trouxe isso a si mesmo. Mas se a brutalidade, supostamente incorporada por ele, ou que o esquema racial ritualmente fabrica como a intenção inevitável e incipiente de seu corpo, se esta é a brutalidade da polícia branca, então esta é uma brutalidade que a polícia encena e desloca a um só tempo. Rodney King, tido para eles como origem e instrumento potencial de toda a violência na cena, foi reduzido a fantasma de agressão racista branca, que pertence a esta agressão racista branca enquanto figura externalizada de sua própria distorção. Ele se torna, no interior desse esquema, nada mais que o lugar no qual a violência racista teme e golpeia o espectro de sua própria ira. Nesse sentido, o circuito de violência atribuído a Rodney King é em si mesmo o circuito racista branco que violentamente nega a si mesmo, apenas para brutalizar o espectro que incorpora sua própria intenção. Este é o fantasma que ele ritualmente produz no lugar do outro racializado.

É precisamente por este corpo negro masculino estar no chão que a agressão se intensifica? Se a paranoia branca é também, em algum nível, homofobia, então essa brutalização não é performada como uma dessexualização ou, alternativamente, como uma punição por uma agressão sexual conjecturada ou desejada? A imagem da polícia sobre Rodney King com seus cassetetes pode ser lida como uma degradação sexual que termina gestualizando e invertendo a cena imaginada de violação sexual que ela parece querer e desprezar. A polícia, portanto, emprega os "ornamentos" e "posições" da cena em serviço de sua negação agressiva.

A reversão e o deslocamento das intenções perigosas mencionadas acima continuaram a ser reiteradas após o veredicto. Em primeiro lugar, há a violência que teve lugar em Los

\footnotetext{
3- Com "episteme racista branca" não pretendo sugerir um sistema estático e fechado de ver, mas uma prática histórica autorrenovada de leitura que, quando não interrompida, tende a estender sua força hegemônica. Claramente, termos como "paranoia branca" não descrevem de qualquer modo totalizante "como pessoas brancas veem", mas são oferecidos aqui como hipérboles teóricas para fazer avançar uma estratégica contra-leitura agressiva.
} 
Angeles, durante a qual a maioria de indivíduos mortos eram negros e [estavam] nas ruas, assassinados pela polícia, portanto repetindo, intensificando e estendendo o escopo da violência contra Rodney King. A intensificação da violência policial contra pessoas racializadas pode ser lida como evidência de que o veredicto foi assumido como mais uma sanção estatal para a violência policial racista. Em segundo lugar, [falemos sobre] os comentários feitos pelo Sr. Bush no dia seguinte ao anúncio do veredicto, nos quais ele condenou a violência pública, destacando primeiro quão lamentável é a violência pública contra a propriedade (!) ${ }^{4}$, e acusando como responsáveis, mais uma vez, aqueles corpos negros nas ruas, como se tais figuras brutalizadas tivessem, como antecipado, ressuscitado e levantado forças contra a polícia. Os grupos envolvidos na violência nas ruas, assim, foram construídos paradoxalmente como os iniciadores de um conjunto de mortes que podem muito bem ter deixado mortos seus próprios corpos, exonerando assim, novamente, a polícia e o estado, e performando uma identificação com o risco fantasmático da comunidade de Simi Valley. Em terceiro lugar, [citemos] a cobertura da mídia sobre a violência nas ruas, a recusa em ler como, onde e por que as fogueiras foram acesas, lojas queimadas, de fato, o que estava sendo articulado na e por meio daquela violência. A bestialização das multidões, consolidada por técnicas de cobertura que pareciam "caçar" pessoas racializadas e figurar sua violência como "sem sentido" ou "bárbara", recapitulou a produção racista do campo visual.

Se a leitura do júri reencenou a cena fantasmática do crime, reiterando e reocupando o status de pessoas brancas nas ruas, sempre já em perigo, e a resposta a tal leitura, agora inscrita como veredicto, foi citar novamente a acusação e reencenar e aumentar o crime, isso foi alcançado em parte por meio da transposição e da fabricação da intenção perigosa. Isso mal chega a ser uma explicação completa sobre as causas da violência racista, mas, quiçá, constitua um momento de sua produção. Ela pode talvez ser descrita como uma forma de paranoia branca que projeta a intenção de ferir, encenada por si própria, e então repete a projeção em escalas crescentemente mais amplas, uma modalidade social específica de compulsão de repetição, que ainda precisamos aprender como ler, sendo essa uma "leitura" performada em nome da lei com efeitos óbvios e consequenciais.

\section{Referências}

BUTLER, Judith. Quadros de guerra: quando a vida é passível de luto? Rio de Janeiro: Civilização Brasileira, 2015.

FANON, Frantz. A experiência vivida do negro. In: FANON, Frantz. Peles negras, máscaras brancas. Salvador: UFBA, 2008. p. 103-126.

4 - Em primeiro de maio de 1992, George H. W. Bush fez um pronunciamento em rede nacional com duração de aproximadamente doze minutos, em que afirmou haver três mil agentes da guarda nacional, exército e agentes treinados e especializados em controle de multidão, somando-se ao contingente de agentes das forças armadas que foram enviados para a Califórnia. Bush justificou o uso da força do Estado com objetivo de restaurar a ordem. Butler retoma e aprofunda sua análise das justificativas éticas amparadas em fenótipos raciais como política de Estado em Quadros de Guerra (2015) ao descrever os arranjos jurídicos internacionais para a transferência de pessoas acusadas de terrorismo à Baía de Guantánamo (N. da R.T.). 
Fabiana A. A. Jardim é docente da Faculdade de Educação (FEUSP). Graduada em ciências sociais (USP), doutora em sociologia (PPGS/USP) e professora da área de sociologia da educação na Faculdade de Educação (USP) e do PPGE/USP. Seus temas de pesquisa são: governamentalidades periféricas, configurações estatais latino-americanas, violência e dispositivos de memória.

Jacqueline Moraes Teixeira é doutora em antropologia social (PPGAS/USP), professora substituta da Faculdade de Educação (USP) e pesquisadora do Centro Brasileiro de Análise e Planejamento (Cebrap). Suas pesquisas localizam-se na área de gênero, sexualidade e religião.

Sebastião Rinaldi é mestrando em educação, na linha "educação e ciências sociais: desigualdades e diferenças" (PPGE/FEUSP), com foco em imigração. Graduado em comunicação social. Trabalha como professor de inglês e tradutor. 
SEÇÃO: ERRATA

Errata: http://dx.doi.org/10.1590/s1517-9702202147460100302E

$\mathrm{Na}$ tradução "Em perigo/perigoso: racismo esquemático e paranoia branca" DOI: https://doi.org/10.1590/s1517-97022020460100302 publicado em Educação e Pesquisa, v. 46, p. 01-09, e-location e460100302, 2020.

Página 01. Nome dos autores e tradutores

Onde se lê:

Sebastião Rinaldi ${ }^{3}$

ORCID: 0000-0001-6272-263X

Leia-se:

Revisão técnica: Sebastião Rinaldi ${ }^{3}$

ORCID: 0000-0001-6272-263X

Educ. Pesqui., São Paulo, v. 47, e470100302E, 2021.

DOI: http://dx.doi.org/10.1590/s1678-4634202147460100302E (c) (i) (3)

This content is licensed under a Creative Commons attribution-type BY-NC. 